COMMENT

DOI: $10.1057 /$ s41599-017-0023-2

\title{
Epistemic responsibility as an edifying force in academic research: investigating the moral challenges and opportunities of an impact agenda in the UK and Australia
}

Jennifer Chubb (iD) ${ }^{1} \&$ Mark Reed ${ }^{2}$

\begin{abstract}
The requirement to anticipate, articulate and evaluate the impact of research is a growing part of academic labor. A research impact agenda in the UK and Australia reflects a drive from Governments to see a return on the public investment of research. Some view this as symptomatic of a marketised higher education system, in which knowledge is a commodity as opposed to an object of intrinsic value and dismiss the latter view as nostalgic and unrealistic. Within a research context where knowledge continues to be politicized, longstanding philosophical concerns concerning the value of knowledge and its purpose are rerehearsed and revisited. Discourse concerning the preservation of freedom in an age of increased accountability can be seen to give rise to increased moral and emotional dissonance amongst pockets of the academic community. At the same time, the academic community can be largely seen to possess a strong moral sense of epistemic responsibility toward the societal contribution of useful knowledge. This piece, based upon research that examined the philosophical challenges with respect to an impact agenda facing academics in the UK and Australia, will serve to provoke further discussion about the challenges posed by an impact agenda whilst also acting as a provocation for academics to locate and harness a sense of epistemic responsibility in order to respond to the impact agenda. This may enable a departure away from narrow conceptions of knowledge and its instrumentalism, thus supporting the academic community and its actors in forming a more holistic view of the value of knowledge within this context.
\end{abstract}

\footnotetext{
${ }^{1}$ University of York, York, YO10 5DD, UK. ${ }^{2}$ Newcastle University, Newcastle upon Tyne, NE1 7RU, UK. Correspondence and requests for materials should be addressed to J.C. (email: jennifer.chubb@york.ac.uk) or to M.R. (email: mark.reed@newcastle.ac.uk)
} 


\section{Introduction}

he requirement to anticipate, articulate and evaluate the societal and economic impact or influence of research has for some time polarized academic opinion. Impact is now a key driver of research funding and assessment in the UK and Australia, with growing interest from other countries that invest significantly in research. Consequently, academics are increasingly required to demonstrate how the knowledge they create demonstrably brings benefit outside the academic context.

Despite the persistence of an ethos supportive of universities as a 'public good' whose value to society has inherent worth (Collini, 2012; Graham, 2002), an impact agenda (if characterized as a topdown political agenda, designed to steer research directions, symptomatic of broader trends towards education as a 'market' - as conceptualised by many of the participants whose accounts follow), has been the source of tension for those unable to reconcile this notion with a sense of academic freedom and autonomy. Initial reactions from the academic community were largely characterized by resistance based on personal, political and philosophical grounds (Collini, 2011; Clegg, 2008; Frodeman, 2017; Oancea, 2010; 2013; Watermeyer, 2014, 2016; Chubb and Watermeyer, 2016; Donovan, 2017; Chubb et al., 2017). Critics of the impact agenda perceived a risk to academic and scientific freedom and presented objections to what they saw as governmental over-interference in the direction and design of academic research (Braben et al., 2009; Ladyman, 2009; Docherty, 2014). However, little is known about the underlying concerns of the academic community beyond this initial response.

In this comment piece, we draw on new empirical research that sheds light on the reasons why the impact agenda in both the UK and Australia provoked negative emotion, and seeks to highlight how the edifying force of epistemic responsibility might form the basis for reframing the impact agenda instead of reinforcing a narrow instrumentalised view of the research culture. In doing so, we seek to provoke discussion of the place of knowledge, whether directly useful or not, within the wider world, whilst also promoting awareness of the heightened sense of epistemic responsibility found in the accounts of our participants - a potentially powerful tool for turning resistance and fear into opportunity.

A total of 51 senior career academics were interviewed in two research-intensive universities in the UK and Australia between 2011 and 2013. Academics from across the disciplines provided their views on the impact agenda and were invited to consider the challenges associated with it. The UK and Australia host two of the most well-developed research assessment systems in the world. At the time the research was conducted, an assessment of the reach and significance of research impact had been introduced to the UK's Research Excellent Framework (which was assessed in 2014) and proposals were being discussed to evaluate research impact in Australia's 2012 Excellence in Innovation Australia trial assessment and there was a subsequent announcement of plans for the implementation of an impact assessment in the Excellence Research Australia process 2018. With growing interest in the assessment of research impact from around the world, the findings of this research provide a foretaste of academic reactions as the impact agenda widens internationally. We seek to highlight differences in epistemic sensibilities that can explain both the hopes and fears of an academy facing an impact agenda.

\section{Contrasting views on impact and the value of knowledge}

The impact agenda was often referred to by participants as synonymous with a utilitarian, instrumentalised conception of research favoring knowledge that leads to a distinct outcome of direct utility to society and the economy. Consequently, participants who struggled to align their work with a clear outcome often expressed how they felt disadvantaged in the context of an increasingly competitive funding environment. For some, this fed into wider narratives about the politicization and marketization of knowledge, resulting in over-regulation and managerialism in the academy (Giroux, 2014; Marginson and Considine, 2000; Naidoo, 2003; Deem, et al., 2008; Holmwood, 2014). Interviewees expressed concern that a fixation on utility could lead to an unduly narrow conceptualization of knowledge and expressed concerns that ranged from the perception that impact was "strangulating" creativity, to concerns about negative effects on career progression for those who could not demonstrate utility.

These results appeared somewhat unsurprisingly dependent upon the type of research being conducted by participants. For example, participants from the life and earth sciences and the social sciences claimed that they were more likely to conduct instrumental research of 'extrinsic' value - or value outside of the academy - and therefore largely perceived impact as an opportunity rather than hindrance. At the opposite end of the scale, participants largely from the arts and humanities and physical sciences conducting less instrumental research expressed deeper concerns. Here, participants tended towards narratives of 'intrinsic' value and were more likely to be ambivalent about impact or see it as a threat. Although the research appears on the surface to reinforce longer standing, perhaps regrettably ingrained perceptions of disciplinary hierarchies and even snobberies, say between the arts and the sciences (Snow, 2012; Bourdieu, 1988), favoring the esteem and intrinsic value associated with pure ${ }^{1}$ research over applied research and practice, our findings also suggest that the impact agenda may bring together the disciplines in less polarized cultures to respond to impact bound by notions of value.

The notion of knowledge as possessing intrinsic or instrumental value was reflected in the accounts of participants from both the arts and the sciences. For example:

“There's no great value in anything except instrumental knowledge."

\section{Literature, Australia, Professor}

"It forces people to think as they're writing the proposal. They are forced to think, well, what is the end result of thisand things like that."

\section{Computer Science, UK, Professor}

A resounding concern for over half of participants, particularly researchers from the arts and humanities and pure sciences, was then that if impact implies utility and disciplines are assumed to be without obvious utility, then the value of their endeavors may be scrutinized. As a result, many participants leapt to the defense of a more holistic understanding of value such as that which enriches society culturally (Briggle, et al., 2015; Belfiore and Bennett, 2007; Belfiore 2015; Benneworth, 2015):

"Look you can't just have a world in which all funding is going to (as important as it is to set up a research for a burn victim or for children who have cancer) those are very important things but we live in a society where other kinds of things are important too and recognise those things for what they are-history, literature, philosophy, the humanities it all addresses a way of, it gives one the wherewithal to live a certain kind of life."

Philosophy, Australia, Professor 
The research confirms that some academics can be seen to be struggling with what Watermeyer (2012) referred to as the "inescapability of academic capitalism" (p 373) - or the inevitability of having to engage in market-like behaviors (Slaughter and Rhoades, 2004). One participant stated that they felt that there was an ethical duty to consider how public money might be spent, claiming that the use of funds to support the arts and humanities was surely more useful and even more ethical than using it for the benefit of large corporations:

"When I hear some of the extreme rhetoric against funding the humanities, it's always, 'why should public money be spent on this useless stuff?', and I think, why are you so happy for public money to be spent on creating big profits for private industries?"

\section{History, Australia, Professor}

But the discourse continued. The concept of value and valuing certain 'goods' like knowledge (epistemic value), was prominent throughout the interviews. Some suggested a hierarchy of value, where instrumental (e.g., economic and commercial) value was in some way "better", or at least easier to measure, than cultural and social value (Oancea et al., 2015, 2017). There was a recurrent observation that those conducting non-instrumental research felt the need to defend their more nuanced forms of impact and appeared to be unsure as to what constituted 'enough' impact. One participant anxiously asked "does that count?" - suggesting that she was unsure about the place and value of her professional activities (Literature, UK, Professor). These questions might imply that non-instrumental researchers feel they have a subtle, deeper effect on society and the economy than can be described in the current terms of an impact agenda where impacts that can be quantified are perceived to be given greater credence:

"It's that expansive thing that education has, that pure research has too. The pleasure for people doing academic jobs rather than going into industry with our skills is that ability to do blue sky stuff."

\section{Performance, UK, Professor}

One participant conducting less instrumental research appeared resigned to the idea that the impact agenda in their country was only concerned with 'useful knowledge'; "at the moment in Australia it's the idea of what's practical" (Literature, Australia, Professor). These accounts convey a deep sense that the political demands of governments in both the UK and Australian contexts might contribute towards the destabilization of traditional virtues or norms associated with academia, both in practice and in principle (Battaly, 2013; Merton, 1942; Williams, 2002). However, at the same time, the research also revealed a community with a strong moral sense of responsibility to contribute towards society. This we refer to as epistemic responsibility-relating to knowledge as an epistemic good for which one has responsibility towards the public and society.

\section{Epistemic responsibility}

Over half the total number of academics interviewed felt that they had a duty or moral responsibility to communicate their work beyond the academy and to generate impact from their work.
"I think you have a duty as an academic to notice that something may be of use and to set in motion a pathway that enables it to be useful."

\section{Physics, UK, Professor}

Almost all participants associated their role with 'responsibility', whereas some suggested that 'duty' was too strong a word. Some participants felt that research communication was important as long as the time and effort spent was proportionate and it was meaningful to do so: "well as far as it is helpful, yes" commented one Australian professor of maths (who seemed a little concerned about explaining pure maths to the public). Others provided caveats such as the idea that it should not be the responsibility of every academic; rather it was a broader role of the university, or those more adept at communication:

"I think it's a bit hard to put the duty wholly on the researcher. I think I'd say it was a responsibility rather than a duty. Yes, I think we do have to assume/hope that we can present what we do to the public."

\section{History, Australia, Professor}

"Yes, well as a community we have a duty and so we need people who are able to do it. That doesn't mean we all need to do it."

\section{Biology, UK, Senior Lecturer}

Of course, one could argue that there is nothing specific about the duty of academics compared to other groups in society who should share responsibility for communicating their knowledge to the public (Barnett, 2000). Instead of privileging the knowledge of researchers over other kinds of knowledge, this perspective argues for researchers and publics to combine their knowledge and experiences in order to achieve beneficial change. As one interviewee described:

"I feel that everyone in the world should be devoted to making the world a better place. That's a religious assertion if you wish, or an ethical one, academics are no different, but they have no special duties beyond that. Their duties are the same as everyone else. We should all be citizens."

$$
\text { Music, UK, Professor }
$$

\section{Conclusion: harnessing responsibility and reframing impact}

The impact agenda can be seen to unearth moral questions about epistemic value and responsbility, with many of the narratives provided by participants implying a tension, increasingly apparent between intellectual ideals about the defense of intrinsic epistemic value, vs. the moral imperative or responsibility that knowledge ought to be instrumentally useful to society.

These positions at first appear at odds and dichotomous, and yet they must be reconciled to respond to the impact agenda. Findings from this research suggest that these positions are dependent upon personal and disciplinary differences and that these differences have strong implications for the perceptions and behaviors of academics within certain disciplinary groupings (Chubb and Watermeyer, 2016; Oancea, 2013). Despite this, what appears to unite academics is the investment they put into the knowledge they create, and the perceived value of the knowledge they so robustly defend, despite its obvious 'use'. 
However, most participants could be seen as complicit with the notion of impact, instead creating 'echo chambers' characterized by despair and resistance. Some of the justifications for resistance found in this research may not of course reflect actual official guidance on impact (e.g., the idea that the UK's Research Excellence Framework only values economic impact, voiced by one of the interviewees quoted earlier in the article). Indeed, there is reason to suggest that individual interpretation(s) of research policy may be responsible for some of the unease felt by participants. However, by recognizing and giving voice to these perceptions, it becomes possible to facilitate dialogue that can help influence future research policy whilst reshaping perceptions.

By voicing the views of our participants here, we seek to inform research policy whilst providing researchers with a mirror in which they can reframe the concept of impact and reflect on their responsibilities as academics. Academics who were interviewed typically felt torn between protecting academic freedom and their "intellectual duty" or "responsibility" to communicate their research and benefit the public who funded their work. However, all participants located a strong sense of epistemic responsibly, reinforcing of intellectual virtues feared to be at risk by those who characterize the impact agenda by noting its corrupting influences.

Our research challenges this tension by proposing "epistemically responsible academic freedom" - espousing the role of responsibility and accountability as enhancing of academic freedom rather than as a distinct right (Gibbs, 2016). Instead of seeing impact as a mere duty to be discharged, epistemic responsibility could be seen as a positive, reinforcing, virtuous moral imperative that competes with the idea of completely unaccountable academic freedom - arguably open to forms of corruption. If impact is reframed in this way, it is no longer a trade-off, but rather it justifies and deepens our characterization of academic freedom and what it means to be an academic today. Reframed in this way, it becomes possible to acknowledge a more holistic understanding of value, accounting (to some extent) for disciplinary diversity and the rich ecology of types of knowledge including both their inherent and explicit forms of 'utility' in the face of an ever-growing impact agenda. This provocation is to all academics to access their motivations for doing research and an appraisal of their epistemic responsibilities, both to themselves as academics and to the public.

Received: 30 May 2017 Accepted: 11 October 2017

Published online: 07 November 2017

\section{Notes}

1 Pure basic research is research carried out for the advancement of knowledge, without working for long-term economic or social benefits (OECD Frascati Manual, (1993) 5th edn. p 50, para. 227)

\section{References}

Barnett R (2000) University knowledge in an age of supercomplexity. Higher Educ 40(4):409-422

Battaly H (2013) Detecting epistemic vice in higher education policy: epistemic insensibility in the seven solutions and the REF. J Philos Educ 47(2):263-280

Belfiore E (2015) 'Impact', 'value' and 'bad economics': making sense of the problem of value in the arts and humanities. Arts Humanities Higher Educ 14 (1):95-110

Belfiore E, Bennett O (2007) Rethinking the social impact of the arts. Int J Cult Policy 13(2):131-151

Benneworth P (2015) Putting impact into context: the Janus face of the public value of arts and humanities research. Arts Humanities Higher Educ 14(1):3-8

Bourdieu P (1988) Homo academicus. (P. Collier, Trans.) Stanford University Press, Stanford, California
Braben D, Allen JF, Amos W, Ashburner M, Ashmore J, Birkhead T, Woodruff P (2009) Only scholarly freedom delivers real 'impact' 1: An open letter to Research Councils UK. The Times Higher Education. http://www. timeshighereducation.co.uk/story.asp?storycode $=408984$. Accessed $25 \mathrm{Mar}$ 2017

Briggle, Frodeman and Holbrook (2015) The Impact of philosophy and the philosophy of impact: a guide to charting more diffuse influences over time http://blogs.lse.ac.uk/impactofsocialsciences/2015/05/26/the-impact-ofphilosophy-and-the-philosophy-of-impact/. Accessed 25 Mar 2017

Chubb J, Watermeyer R (2016) Artifice or integrity in the marketization of research impact? Investigating the moral economy of (pathways to) impact statements within research funding proposals in the UK and Australia. Studies in Higher Education, p 1-13

Chubb J, Watermeyer R, Wakeling P (2017) Fear and loathing in the Academy?: The role of emotion in response to an impact agenda in the UK and Australia. High Edu Res and devt 36(3):555-568

Clegg S (2008) Academic identities under threat? Br Educ Res J 34(3):329-345

Collini S. (2011). Research must not be tied to politics. The Guardian. http://www. theguardian.com/commentisfree/2011/apr/01/research-arts-and-humanitiesresearch-council. Accessed 2 Mar 2015

Collini S (2012) What are universities for? Penguin, UK

Deem R, Hillyard S, Reed M (2008) Knowledge, higher education, and the new managerialism: the changing management of UK universities. Oxford University Press, Oxford

Docherty T (2014) Thomas Docherty on academic freedom. Times Higher Education. http://www.timeshighereducation.co.uk/features/thomas-dochertyon-academic-freedom/2017268.article. Accessed 5 Mar 2015

Donovan C (2017) For ethical 'impactology'. J Resp Innov 1-6

Frodeman R (2017) The impact agenda and the search for a good life. Palgrave Communications. 3:17003. http://dx.doi.org/10.1057/palcomms.2017.3

Gibbs A (2016) Academic freedom in international higher education: right or responsibility? Ethics Educ 11(2):175-185

Giroux H (2014) Neoliberalism's war on Higher Education. Haymarket Books, Chicago, IL

Graham G (2002) Universities, the recovery of an idea. Societas Book 1. Imprint Academic, London

Holmwood J (2011). The ideas of a public university. A Manifesto for the Public University, pp 12-26

Holmwood J (2014) From social rights to the market: neoliberalism and the knowledge economy. Int J Lifelong Educ 33(1):62-76

Ladyman J (2009) Scientists call for a revolt against grant rule they claim will end blue skies research. Times Higher Education. http://www. timeshighereducation.co.uk/405350. Accessed 5 Mar 2015

Marginson S, Considine M (2000) The enterprise university

Merton RK (1942) A note on science and democracy. J Legal Pol Soc 1:115

Naidoo R (2003) Repositioning higher education as a global commodity: opportunities and challenges for future sociology of education work. Br J Soc Educ 24(2):249-259

Oancea A (2010) Research assessment in the United Kingdom: issues of concern. Int Soc Sci Council (2010) World Social Science Report

Oancea A (2013) Interpretations of research impact in seven disciplines. Eur Educ Res J 12(20):242-250

Oancea A, Florez-Petour T, Atkinson J (2015) The Ecologies and Economy of Cultural Value from Research. International Journal of Cultural Policy. http://dx.doi.org/10/1080/10286632.2015.1128418. Accessed 19 Oct 2017

Oancea A, Florez-Petour T, Atkinson J (2017) Qualitative network analysis tools for the configurative articuilation of cultural value and impact from research. Research Evaluation

Slaughter S, Rhoades G (2004) Academic capitalism and the new economy. John Hopkins University Press, Baltimore, MD

Snow CP (2012) The two cultures. Cambridge University Press, Cambridge

Watermeyer R (2012) "From engagement to impact? articulating the public value of academic research." Tert Educ Manag 18(2):115-30

Watermeyer R (2014) Issues in the articulation of 'impact': the responses of UK academics to 'impact' as a new measure of research assessment. Stud Higher Educ 39(2):359-377

Watermeyer R (2016) Impact and REF: issues and obstacles. Stud Higher Educ 41 (2):199-214

Williams B (2002) Truth and Truthfulness: An Essay in Genealogy. Cambridge University Press, Cambridge

\section{Additional information}

Competing interests: Jennifer Chubb and Mark Reed both consult for Fast Track Impact.

Reprints and permission information is available online at http://www.nature.com/ reprints 
Publisher's note: Springer Nature remains neutral with regard to jurisdictional claims in published maps and institutional affiliations.

(c) Open Access This article is licensed under a Creative Commons Attribution 4.0 International License, which permits use, sharing, adaptation, distribution and reproduction in any medium or format, as long as you give appropriate credit to the original author(s) and the source, provide a link to the Creative Commons license, and indicate if changes were made. The images or other third party material in this article are included in the article's Creative Commons license, unless indicated otherwise in a credit line to the material. If material is not included in the article's Creative Commons license and your intended use is not permitted by statutory regulation or exceeds the permitted use, you will need to obtain permission directly from the copyright holder. To view a copy of this license, visit http://creativecommons.org/ licenses/by/4.0/.

(C) The Author(s) 2017 